\title{
ORIGINAL ARTICLE \\ Substance use in young adults with pediatric-onset spinal cord injury
}

\author{
M Hwang ${ }^{1,2}$, KM Chlan ${ }^{2}$, LC Vogel ${ }^{2,3}$ and K Zebracki ${ }^{2,3}$
}

\section{Study design: Cross-sectional survey}

Objectives: To assess the prevalence of substance use in young adults with pediatric-onset spinal cord injury (SCI) and its relationship with demographic factors, and medical and psychosocial outcomes.

Setting: Young adults living in the United States who received pediatric SCl care at one of three $\mathrm{SCl}$ programs at the Shriners Hospitals for Children.

Methods: Individuals aged 21-25 years who had sustained SCI before the age of 19 were interviewed with a structured questionnaire including standardized outcome measures: FIM, Satisfaction with Life Scale (SWLS), Short-Form 12 Health Survey (SF-12), Patient Health Questionnaire-9 (PHQ-9) Depression Scale, and Craig Handicap Assessment and Recording Technique (CHART).

Results: Sample included 215 individuals with a mean age at interview of 23.3 (s.d.=0.9) years and mean age at injury of 13.2 (s.d.=4.9) years. In all, $24 \%$ had a college degree, 36\% were employed and $12 \%$ were married. Regular substance use was reported by $28 \%$ for tobacco, $55 \%$ for alcohol and $11 \%$ for marijuana. Tobacco use was associated with depressive symptoms and unemployment; alcohol use was associated with having a college degree, single status and independent mobility; and marijuana use was associated with not having a college degree. There were no significant associations between substance use and injury-related factors or life satisfaction.

Conclusion: Substance use in young adults with pediatric-onset SCl was associated with factors such as education, employment, marital status and depressive symptoms. Clinicians caring for youth with $\mathrm{SCl}$ should counsel patients and caregivers regarding the use of substances and potential associations with outcomes in adulthood.

Spinal Cord (2012) 50, 497-501; doi:10.1038/sc.2012.8; published online 28 February 2012

Keywords: substance use; pediatric-onset spinal cord injury; outcomes

\section{INTRODUCTION}

Substance use is known to contribute to the onset of spinal cord injury (SCI) as well as to affect outcomes following SCI. ${ }^{1}$ Alcohol and drug intoxication rates range from 25 to $53 \%$ of the traumatic incidents leading to SCI. ${ }^{2}$ The prevalence rates of alcohol use in persons with SCI have been reported to be $50-90 \%$ depending on age or time since injury, whereas prevalence of marijuana use has been reported to be $16-26 \%$ depending on age, duration of injury or presence of pain. 3,4 Cigarette smoking in veterans with SCI ranges from 18 to $22 \%$ and has been associated with alcohol use and depression. ${ }^{5}$ These prevalence rates are comparable to those reported for the general population. The National Health Interview Survey of 2009 reported 52\% of adults age $\geqslant 18$ to be regular drinkers and $21 \%$ of adults as current cigarette smokers, with the prevalence of both substances decreasing with increasing age, whereas higher education level was positively associated with alcohol use and negatively associated with cigarette smoking. ${ }^{6}$ Long-term use of substances in individuals with SCI can lead to increased incidence or worsening of SCI-related complications such as pressure ulcers, urinary tract infections or pulmonary dysfunction, as well as psychological problems including depression, anxiety, and substance dependency and abuse. ${ }^{1}$

The majority of the literature on substance use in SCI is focused on adults, many of whom have sustained their injury after the age of 18, and thus, may cope with their SCI differently than those injured as a child or adolescent. Individuals who have sustained a SCI in youth are unique in that the injury affects the development of both physical and psychological maturation, and they must live with their disability and associated complications for a longer duration of time relative to the adult-onset SCI population. ${ }^{7}$ As these children and adolescents progress into young adulthood, their physical disability can inhibit integration with peers, leading to social isolation and withdrawn and depressed mood, which may lead to the use of substances as a method of coping with such problems. Also, as in the general population, increased independence in decision-making that accompanies progression into adulthood can lead to new challenges and experiences, including experimentation with substances, which may be habit-forming. On the other hand, owing to their SCI, these individuals most likely have been followed closely by healthcare providers since childhood, and thus may be relatively more health-conscious compared with their able-bodied peers and possibly incorporate positive methods of coping with their disability.

The purpose of this study was to assess the prevalence of substance use in young adults with pediatric-onset SCI and to determine demographic and injury-related factors as well as the outcomes associated with substance use in this population. We focused on the age group between $21-25$ years, as this is a time in which individuals experience profound change, exploration of possible life directions and decision-making that has lasting implications. Risk behaviors,

${ }^{1}$ Marquette University, Milwaukee, WI, USA; ${ }^{2}$ Shriners Hospitals for Children, Chicago, IL, USA and ${ }^{3}$ Rush Medical College, Chicago, IL, USA Correspondence: Dr K Zebracki, Department of Psychology, Shriners Hospitals for Children, 2211 N. Oak Park Ave, Chicago, IL 60707, USA. E-mail: kzebracki@shrinenet.org

Received 3 November 2011; revised 23 December 2011; accepted 23 January 2012; published online 28 February 2012 
such as substance use, also peak in the early 20 s as a result of decreased parental monitoring and exploration of new and different identities. ${ }^{8}$ Based on the literature reviewed and the unique circumstances of maturing into adulthood with a disability, we hypothesized that (1) the prevalence of substance use would be lower than that of the age-matched general population and the adult-onset SCI population; (2) the prevalence of substance use will differ depending on demographic and injury-related factors (that is, education, marital status, level and completeness of injury) and the presence of SCI-associated medical complications (that is, pain, urinary tract infections, pressure ulcers, and spasticity); and (3) the substance use may be associated with poor psychosocial outcomes, less participation and decreased life satisfaction.

\section{METHODS}

\section{Participants}

This cross-sectional study used the data collected through annual telephone interviews from individuals enrolled in a larger longitudinal outcome study of adults with pediatric-onset SCI. Participants were individuals who had sustained a SCI before age 19 and were between 21 and 25 years of age at the time of interview. These individuals had been former patients at one of the three pediatric SCI specialty programs at the Shriners Hospitals for Children: Chicago, Philadelphia and Northern California.

\section{Instruments}

A structured questionnaire was used to collect demographic information including age, gender, race, education, marital and employment status, as well as information on medical complications encountered during the previous year. Injury-related information and medical history were obtained through medical chart reviews and the hospital system's SCI database. The following information was obtained regarding substance use: current use, frequency of use and type of substance (tobacco, alcohol, marijuana, cocaine or other illicit drugs). Frequency of use was categorized as daily, weekly, monthly, yearly or never.

Standardized measures were included to assess outcomes. Functional status was measured with the motor and socio-cognitive scores of the FIM. (The service marks and trademarks associated with the FIM instrument are all owned by the Uniform Data System for Medical Rehabilitation, a division of UB Foundation Activities, Inc. ('UDSMR'). The use of the FIM instrument to collect data for this research study was authorized and conducted in accordance with the terms of a special purpose license granted to Licensee by the Uniform Data System for Medical Rehabilitation, a division not been processed by UDSMR. The patient data collected due the course of this research study has UDSMR. No implication is intended that such data has been or will be subjected to UDSMR's standard data processing procedures or that it is otherwise comparable to data processed by UDSMR. $)^{9}$ Health status was assessed with the physical and mental component scores of the Short-Form 12 (SF-12), which measures the individual's perception of health, with higher scores indicating greater perceived health. ${ }^{10}$ Global life satisfaction was assessed with the Satisfaction with Life Scale (SWLS), which consists of five statements to which individuals rate their degree of agreement on a scale of one (strongly disagree) to seven (strongly agree), with higher scores reflecting higher life satisfaction. ${ }^{11}$ The Patient Health Questionnaire-9 (PHQ-9) was used to assess depressive symptoms in participants and is comprised of nine statements that reflect the diagnostic elements of depression as given in the Diagnostic and Statistical Manual, Fourth Edition. ${ }^{12}$ The Craig Handicap Assessment and Recording Technique (CHART) was used to assess community participation and consists of six separate subscales of physical independence, cognitive independence, mobility, occupation, social integration and economic selfsufficiency. Each subscale has a maximum 100 points, with higher scores indicating higher community participation. ${ }^{13}$

\section{Data analyses}

Substance use was classified as 'regular use' if frequency of use was reported as monthly, weekly or daily use and 'no use' if frequency of use was yearly or never. $\chi^{2}$ test was used to examine relationships between substance use and categorical variables. Relationship between substance use and continuous variables were examined with the Mann-Whitney $U$ test. Stepwise logistic regression analyses were then conducted on each of the substances controlling for variables significantly associated on bivariate analyses to determine independent factors predictive of substance use. Although use of cocaine or other illicit drugs were inquired, only one participant responded positive to use, and thus analyses were conducted for tobacco, alcohol and marijuana.

\section{Statement of ethics}

This study was approved by the Institutional Review Board at the three Shriners hospitals and is registered in a public access database at www.clinicaltrialsgov. We certify that all applicable institutional and governmental regulations concerning the ethical use of human volunteers were followed during the course of this research.

\section{RESULTS}

\section{Descriptive characteristics}

Demographic and injury-related characteristics are summarized in Table 1 . Of the 215 participants, $58.5 \%$ were male, $85.1 \%$ were Caucasian and $51.6 \%$ had tetraplegia. Mean age of participants was $23.4 \pm 0.9$ years, and mean age at injury was $13.2 \pm 4.9$ years, with $25.6 \%$ of the participants sustaining their injury before the age of 13 . Prevalence rates of regular substance use were $27.9 \%$ for tobacco, $55.4 \%$ for alcohol and $10.7 \%$ for marijuana (Table 2). These rates are considerably lower than the age-matched general population, which were reported to be $35-45 \%$ for tobacco, $78-82 \%$ for alcohol and $30-32 \%$ for marijuana. ${ }^{14}$ However, our participants' substance use prevalence rates were similar to that reported for adult-onset SCI population, $3,4,15$ with the exception of higher prevalence of tobacco use compared to the 16-22\% reported for the adult-onset SCI population..$^{5,16}$

\section{Substance use and demographics, injury-related factors and medical complications}

Tobacco use was higher in participants who were unemployed than in those who were employed either full- or part-time (38 vs $21 \%$ ) (Table 3). Alcohol use was higher in participants who were Caucasian (60 vs $26 \%$ non-Caucasian), had a college degree ( 80 vs $47 \%$ no college degree), were employed (70 vs $45 \%$ unemployed), had higher annual income $(44 \%,<\$ 10000$ vs $65 \%, \$ 10000-29999$ vs $77 \%$, greater than $\$ 30000$ ), were single (59 vs $31 \%$ married) and able to drive independently (67 vs $35 \%$ cannot drive independently). Marijuana use was more prevalent in males (14 vs $6 \%$ female) and in those without a college degree ( 13 vs $2 \%$ college degree). While the number of individuals living with a parent or guardian was significantly greater for those with tetraplegia (58 vs $37 \%$ paraplegia), there was no significant difference in the prevalence of substance use between those living independently and those living with a guardian. There were also no significant associations between the substance use and any injury-related factors such as level, severity or duration of injury. Associations with medical complications revealed that individuals with regular alcohol use had significantly lower incidence of urinary tract infections (64 vs $82 \%$ ) and chronic medical conditions (11 vs $22 \%$ ) compared with individuals with no use. There were no significant associations between substance use and any of the other medical complications investigated.

\section{Substance use and standardized outcome measures}

Tobacco use was significantly associated with depressive symptoms $(P<0.05)$, whereas alcohol use was associated with higher 
Table 1 Characteristics of participants

\begin{tabular}{|c|c|c|c|c|c|}
\hline & & & & & Mean \pm s.d. or $\%$ \\
\hline Number of & ticipants & & & & 215 \\
\hline Gender & & & & & \\
\hline Male & & & & & 58.5 \\
\hline Age at inter & $N$ (years & & & & $23.4 \pm 0.9$ \\
\hline Age at injur & (ears) & & & & $13.2 \pm 4.9$ \\
\hline Duration of & ury (yea & & & & $10.3 \pm 5.0$ \\
\hline Education & & & & & \\
\hline High scho & diploma & & & & 97.7 \\
\hline College $d$ & & & & & 23.7 \\
\hline Caucasian & & & & & 85.1 \\
\hline Married & & & & & 12.1 \\
\hline Employed, $f$ & part-tim & & & & 35.3 \\
\hline Individual it & me & & & & \\
\hline$<\$ 1000$ & & & & & 36.7 \\
\hline$\$ 10000$ & 999 & & & & 22.3 \\
\hline$\geqslant \$ 3000$ & & & & & 15.2 \\
\hline Missing ( & 66) & & & & 25.8 \\
\hline Lives with $\mathrm{g}$ & dian & & & & 47.4 \\
\hline Tetraplegia & & & & & 51.6 \\
\hline Complete in & & & & & 73.5 \\
\hline Severity & & & & & \\
\hline C1-C4 Al & $A B C$ & & & & 11.2 \\
\hline C5-C8 Al & $A B C$ & & & & 35.3 \\
\hline T1-S5 Al & $A B C$ & & & & 43.3 \\
\hline AIS D & & & & & 8.8 \\
\hline Missing ( & & & & & 1.4 \\
\hline Etiology & & & & & \\
\hline Vehicular/ & destrian & & & & 51.6 \\
\hline Violence & & & & & 11.2 \\
\hline Falls/flyin & bjects & & & & 4.7 \\
\hline Sports & & & & & 18.1 \\
\hline Medical/s & jical & & & & 11.2 \\
\hline Other/unk & & & & & 3.3 \\
\hline Medical con & ications & & & & \\
\hline Pressure & & & & & 38.3 \\
\hline Urinary tr & infectic & & & & 72.2 \\
\hline Pain & & & & & 66.0 \\
\hline Autonomi & ysreflex & & & & 49.1 \\
\hline Spasticity & & & & & 46.5 \\
\hline Chronic $\mathrm{m}$ & ical con & $i^{c}$ & & & 15.6 \\
\hline $\begin{array}{l}\text { aAIS, America } \\
\text { bPrevalence o } \\
\text { cChronic med } \\
\text { bifida, muscul }\end{array}$ & $\begin{array}{l}\text { pinal Inju } \\
\text { edical co } \\
\text { conditior } \\
\text { dystrophy }\end{array}$ & $\begin{array}{l}\text { Association } \\
\text { ications en } \\
\text { sthma, car } \\
\text { ncer and o }\end{array}$ & $\begin{array}{l}\text { ipairment Sc } \\
\text { intered in th } \\
\text { : disease, hy } \\
\text { rs. }\end{array}$ & $\begin{array}{l}\text { year period befor } \\
\text { ension, stroke, d }\end{array}$ & $\begin{array}{l}\text { re interview. } \\
\text { iabetes, spina }\end{array}$ \\
\hline Substance & Daily & Weekly & Monthly & Yearly/Never & Regular use ${ }^{a}$ \\
\hline Tobacco & 20.9 & 3.3 & 3.7 & 72.1 & 27.9 \\
\hline Alcohol & 0.9 & 24.2 & 30.2 & 44.6 & 55.4 \\
\hline Marijuana & 4.7 & 3.7 & 2.3 & 89.3 & 10.7 \\
\hline
\end{tabular}

Regular use: use of substance at least monthly.

socio-cognitive independence $(P<0.01)$, better perceived physical health and increased community participation $(P<0.05)$. Marijuana use was not associated with any outcome measure (Table 4$)$.
Table 3 Substance use and demographics, injury-related factors and medical complications

\begin{tabular}{|c|c|c|c|c|c|c|}
\hline & \multicolumn{2}{|c|}{ Tobacco } & \multicolumn{2}{|c|}{ Alcohol } & \multicolumn{2}{|c|}{ Marijuana } \\
\hline & $\chi^{2}$ & $d f$ & $\chi^{2}$ & $d f$ & $\chi^{2}$ & $d f$ \\
\hline Gender & 0.832 & 1 & 0.396 & 1 & $4.102^{*}$ & 1 \\
\hline Race & 0.552 & 1 & $11.143^{\dagger}$ & 1 & 0.399 & 1 \\
\hline College degree & 3.583 & 1 & $16.967^{\dagger}$ & 1 & $5.342 *$ & 1 \\
\hline Employment & $4.870^{*}$ & 1 & $9.110^{\dagger}$ & 1 & 3.246 & 1 \\
\hline Annual income ${ }^{a}$ & 2.231 & 2 & $14.626^{\dagger}$ & 2 & 3.383 & 2 \\
\hline Married & 0.109 & 1 & $7.230^{\dagger}$ & 1 & 0.022 & 1 \\
\hline Drive independently & 0.585 & 1 & $21.292^{\dagger}$ & 1 & 0.577 & 1 \\
\hline Live with guardian & 0.237 & 1 & 2.247 & 1 & 0.162 & 1 \\
\hline Age at injury ${ }^{b}$ & 1.445 & 3 & 5.319 & 3 & 1.567 & 3 \\
\hline AIS severity & 3.840 & 3 & 7.411 & 3 & 0.666 & 3 \\
\hline Complete/incomplete & 0.051 & 1 & 2.715 & 1 & 0.687 & 1 \\
\hline Tetra/paraplegia & 2.708 & 1 & 1.054 & 1 & 0.121 & 1 \\
\hline Etiology ${ }^{c}$ & 5.369 & 5 & 2.185 & 5 & 3.997 & 5 \\
\hline Pressure ulcer & 2.354 & 1 & 2.510 & 1 & 0.290 & 1 \\
\hline Urinary tract infection & 0.892 & 1 & $8.460^{*}$ & 1 & 0.087 & 1 \\
\hline Pain & 1.054 & 1 & 0.030 & 1 & 3.150 & 1 \\
\hline Autonomic dysreflexia & 0.273 & 1 & 1.294 & 1 & 0.100 & 1 \\
\hline Spasticity & 0.469 & 1 & 3.049 & 1 & 0.332 & 1 \\
\hline Chronic medical condition & 1.371 & 1 & $4.600^{*}$ & 1 & 0.728 & 1 \\
\hline
\end{tabular}

$\chi^{2}$ test, ${ }^{*} P<0.05 ; \uparrow P<0.01$.

Income categories: $<\$ 10000 ; \$ 10000-29999 ; \geqslant \$ 30000$

${ }^{b}$ Age at injury categories: 0-5 y; 6-12 y; 13-15 y; 16-18 y.

"Etiology categories: vehicular/pedestrian; violence; fall/flying objects; sports; medical/surgical; other/unknown.

\section{Predictors of substance use}

Logistic regression results indicate that both employment status (that is, unemployment) and the presence of depressive symptoms contribute independently to tobacco use $(P<0.05)$ (Table 5). Among the variables associated with alcohol use, having a college degree $(P<0.05)$ and being single were found to contribute most in predicting regular alcohol drinking $(P<0.01)$, while independent mobility $(P<0.01)$ was also a significant predictor for use. For marijuana use, male gender dropped out of the regression model, leaving only college degree as a predictor, such that those with a college degree were less likely to use marijuana $(P<0.05)$.

\section{DISCUSSION}

To our knowledge, this is the first investigation regarding substance use in individuals who had sustained a pediatric-onset SCI. In our study population of young adults, we found the prevalence rates of substance use to be considerably lower than that reported for the agematched general population. ${ }^{14}$ Potential reasons for this difference may include participants having limited access to substances, either as a result of infrequent outings for purchase or limited functional ability to actually use the substances or increased monitoring by caregivers. It is important to note, however, that significant differences in substance use between those who live independently and those who live with a parent or guardian and between those with tetraplegia and with paraplegia were not found (Table 3). The participants were of legal age capable of making one's own decision, and thus substance use was most likely the result of the individual's choice to use, with level of injury or caregiver monitoring being less of a contributing factor. The presence of common SCI-related complications (for example, pressure ulcers, urinary tract infections) can also reduce the possibility of using substances, as smoking or drinking may impede healing or aggravate 
Table 4 Substance use and outcome measures

\begin{tabular}{|c|c|c|c|c|c|c|}
\hline & \multicolumn{2}{|c|}{ Tobacco } & \multicolumn{2}{|c|}{ Alcohol } & \multicolumn{2}{|c|}{ Marijuana } \\
\hline & No & Yes & No & Yes & No & Yes \\
\hline FIM socio-cognitive & 103.50 & 101.74 & $92.65^{\dagger}$ & $110.78^{\dagger}$ & 103.17 & 101.67 \\
\hline SF-12 physical & 101.53 & 106.72 & $91.71^{*}$ & $111.49^{*}$ & 103.21 & 101.37 \\
\hline SF-12 mental & 103.78 & 101.03 & 96.95 & 107.55 & 104.01 & 95.04 \\
\hline \multicolumn{7}{|l|}{ CHART } \\
\hline Physical independence & 101.72 & 111.53 & $93.26^{*}$ & $113.24^{*}$ & 103.35 & 113.74 \\
\hline Cognitive independence & 105.55 & 94.83 & 95.23 & 107.91 & 104.35 & 87.93 \\
\hline Mobility & 107.97 & 106.30 & $86.16^{\dagger}$ & $124.53^{\dagger}$ & 109.45 & 91.33 \\
\hline Occupation & 106.48 & 102.98 & 97.77 & 111.65 & 106.78 & 95.07 \\
\hline
\end{tabular}

Values are mean rank for Mann-Whitney $U$ test, ${ }^{*} P<0.05 ;{ }^{\dagger} P<0.01$.

aSWLS, Satisfaction with Life Scale.

bPHQ-9, Primary Health Questionnaire.

cCHART, Craig Handicap Assessment and Recording Technique.

Table 5 Logistic regression models for predictors of substance use

\begin{tabular}{|c|c|c|c|c|c|c|}
\hline Substance & Predictor & $B$ & s.e. & $P$ & Odds ratio & $95 \% \mathrm{Cl}$ \\
\hline \multirow[t]{2}{*}{ Tobacco $^{a}$} & Employment & -1.502 & 0.671 & 0.025 & 0.223 & $0.060-0.830$ \\
\hline & Depressive symptoms & 0.171 & 0.081 & 0.034 & 1.187 & $1.013-1.390$ \\
\hline \multirow[t]{3}{*}{ Alcohol $^{b}$} & College degree & 2.682 & 1.124 & 0.017 & 14.619 & $1.613-132.455$ \\
\hline & Married & -2.224 & 0.765 & 0.006 & 0.108 & $0.024-0.484$ \\
\hline & CHART mobility & 0.082 & 0.029 & 0.006 & 1.085 & $1.024-1.149$ \\
\hline Marijuana $^{c}$ & College degree & -2.047 & 1.036 & 0.048 & 0.129 & $0.017-0.983$ \\
\hline
\end{tabular}

aHomer-Lemeshow Goodness of Fit test: $\chi^{2}=5.859, \mathrm{df}=7, P=0.556$; Nagelkerke $R^{2}=0.308$; Correct prediction $73.6 \%$.

bHomer-Lemeshow Goodness of Fit test: $\chi^{2}=4.717, \mathrm{df}=7, P=0.694$; Nagelkerke $R^{2}=0.473$; Correct prediction $79.6 \%$.

cHomer-Lemeshow Goodness of Fit test: $\chi^{2}=0.326, \mathrm{df}=2, P=0.850$; Nagelkerke $R^{2}=0.066$; Correct prediction $89.3 \%$.

symptoms. Alternatively, it is very likely that our participants were followed regularly by healthcare professionals as they matured into adulthood, ${ }^{17}$ and thus may have relatively more health-conscious behavior, which would lessen the possibility of using potentially harmful substances. Similar reasons may also explain why our findings were similar to the rates of alcohol and marijuana use reported for the adult-onset population. ${ }^{3,4,15}$ The prevalence of tobacco use, however, was somewhat higher in our subjects than that reported for the adultonset SCI population. ${ }^{5,16,18}$ This is consistent with the trend in the general population where the rate of cigarette smoking is higher in younger individuals and decreases with increasing age. ${ }^{6}$ This tendency may be accentuated in the SCI population in which the incidence of cardiovascular complications tends to rise with increasing age and duration of injury. ${ }^{16}$

Logistic regression analyses indicated that having a college degree and being single were highly predictive of regular alcohol drinking in our study population. This is similar to the demographic profile for alcohol drinkers in the age-matched general population, which reflect higher levels of independence and social participation. ${ }^{6}$ Similar findings have been reported for the adult-onset SCI population in which higher education and income levels were associated with regular and more frequent alcohol use. ${ }^{15,19}$ It is possible that our participants who obtained higher education levels and active employment status had utilized adaptive coping strategies in their path to adulthood, and thus were able to successfully integrate into their communities and participate in activities, which may involve social drinking. Tobacco use was significantly associated with unemployment and having depressive symptoms, and these findings replicate the relationship established between smoking and depression in the general population. ${ }^{20}$ The relationship between depression and unemployment has been reported in a larger cohort of adults with pediatric-onset $\mathrm{SCI}^{21}$ as well as in the adult-onset SCI population. ${ }^{22}$ Considering the lower rate of employment of SCI individuals compared with the general population $^{23}$ and its association with depression, cigarette smoking is a health behavior that should be monitored closely in the younger SCI population who are entering the stage of pursuing social and financial independence as well experimenting in different lifestyles. ${ }^{7}$ Marijuana use was associated only with not having a college degree after male gender dropped out of the regression model. This is similar to findings by Young et al. ${ }^{4}$ where lower education levels in addition to higher perceived stress were associated with marijuana use in the adult-onset SCI population.

An interesting finding in our population was that the substance use was not associated with an increased incidence of medical complications. This is in contrast to the adult-onset SCI population in which all three substances have been associated with increased incidence of 
pressure ulcer, hospitalizations and pain. ${ }^{16,18,24,25}$ In our study, alcohol was the only substance that was significantly associated with any medical complications; regular alcohol drinkers had less incidence of urinary tract infection and chronic medical conditions, such as hypertension or diabetes, compared with the non-drinkers. The absence of such medical complications possibly allowed increased participation in social or recreational activities, which include drinking. As our study participants were younger and more likely in better physical health compared with the older SCI individuals, it is possible that the incidence of such complications was lower, and thus, a significant association with substance use could not have been established. However, as many SCI-related complications are known to develop with increasing duration of injury, change in patterns of substance use should be monitored in addition to the medical changes that occur over time.

\section{Limitations}

Several study limitations need to be considered when interpreting the results. Data were collected through self-report of substance use. Individuals may have underreported the use to provide perceived socially acceptable response; however, as rapport was well established and confidentially assured, we believe responses were accurate reflections of the sample. Also, abuse or misuse of substances was not assessed. Use of standardized measures such as the Alcohol Use Disorders Identification Test (AUDIT) ${ }^{26}$ or Severity of Dependence Scale (SDS) ${ }^{27}$ would have provided added information on alcohol and marijuana abuse, respectively. In addition, actual quantity of use for each substance was not assessed, from which more detailed relationships between substance use and demographic, psychosocial or medical outcomes could have been elicited. Another limitation is the representativeness of our study population. As all participants had previously received care from a single pediatric specialty hospital system and were mostly Caucasian $(85 \%)$, our findings cannot be generalized to include those who received care at different facilities or those of other race, whose demographic characteristics and substance use patterns could have possibly led to different results. Finally, as this was a cross-sectional study, our findings are correlational and cannot determine a causal relationship between substance use and associated factors.

\section{Conclusion}

The prevalence of tobacco, alcohol and marijuana use were lower than the general population, but similar socio-demographic and outcome factors were predictive of use in our study population. Clinicians caring for children and adolescents with SCI should counsel patients and their caregivers regarding the use of substances and its potential associations with future outcomes. Further research is needed to determine longitudinal changes in substance use and abuse patterns in association with life changes, as well as to determine patterns of illicit drug use and misuse of prescription medications in this unique population of individuals with pediatric-onset SCI.

\section{DATA ARCHIVING}

There were no data to deposit.

\section{CONFLICT OF INTEREST}

The authors declare no conflict of interest.

\section{ACKNOWLEDGEMENTS}

The study was funded by the Shriners Hospitals for Children - Chicago and NIDDR Advanced Rehabilitation Research Training Grant H133P080005.

1 Radnitz CL, Tirch D. Substance misuse in individuals with spinal cord injury. Int J Addict 1995; 30: 1117-1140.

2 McKinley WO, Kolakowsky SA, Kreutzer JS. Substance abuse, violence, and outcome after traumatic spinal cord injury. Am J Phys Med Rehabil 1999; 78: 306-312.

3 Heinemann AW, Doll MD, Armstrong KJ, Schnoll S, Yarkony GM. Substance use and receipt of treatment by persons with long-term spinal cord injuries. Arch Phys Med Rehabil 1991; 72: 482-487.

4 Young ME, Rintala DH, Rossi D, Hart KA, Fuhrer MJ. Alcohol and marijuana use in a community-based sample of persons with spinal cord injury. Arch Phys Med Rehabil 1995; 76: 525-532.

5 Weaver FM, Smith B, LaVela SL, Evans CT, Ullrich P, Miskevics S et al. Smoking behavior and delivery of evidence-based care for veterans with spinal cord injuries and disorders. J Spinal Cord Med 2011; 34: 35-45.

6 Pleis JR, Ward BW, Lucas JW. Summary health statistics for U.S. adults: National Health Interview Survey, 2009. National Center for Health Statistics. Vital Health Stat $102010,1-207$.

7 Vogel LC, Chlan KM, Zebracki K, Anderson J. Long-term outcomes of adults with pediatric-onset spinal cord injuries as a function of neurologic impairment. J Spinal Cord Med 2011; 34: 60-66.

8 Arnett JJ. Emerging adulthood. A theory of development from the late teens through the twenties. Am Psycholol 2000; 55: 469-480.

9 Granger CV, Hamilton BB, Linacre JM, Heinemann AW, Wright B. Performance profiles of the functional independence measure. Am J Phys Med Rehabil 1993; 72: 84-89.

10 Ware Jr J, Kosinski M, Keller SD. A 12-Item Short-Form Health Survey: construction of scales and preliminary tests of reliability and validity. Med Care 1996; 34: 220-233.

11 Pavot W, Deiner E. Review of the satisfaction with life scale. Psychol Assess 1993; 5: 164-172.

12 Bombardier $\mathrm{CH}$, Richards JS, Krause JS, Tulsky D, Tate DG. Symptoms of major depression in people with spinal cord injury: implications for screening. Arch Phys Med Rehabil 2004; 85: 1749-1756.

13 Hall KM, Dijkers M, Whiteneck G, Brooks CA, Krause JS. The Craig Handicap Assessment and Reporting Technique (CHART): metric properties and scoring. J Rehabil Outcomes Meas 1998; 2: 519-526.

14 Substance Abuse and Mental Health Services Administration. Results from the 2009 National Survey on Drug Use and Health. vol. I. Summary of National Findings (Office of Applied Studies, NSDUH Series H-38A, HHS Publication No. SMA 10-4586 Findings): Rockville, MD, 2010.

15 Tate DG, Forchheimer MB, Krause JS, Meade MA, Bombardier CH. Patterns of alcohol and substance use and abuse is persons with spinal cord injury: risk factors and correlates. Arch Phys Med Rehabil 2004; 85: 1837-1847.

16 Wahman K, Nash MS, Lewis JE, Seiger A, Levi R. Increased cardiovascular disease risk in Swedish persons with paraplegia: the Stockholm spinal cord injury study. J Rehabil Med 2010; 42: 489-492.

17 Anderson CJ, Johnson KA, Klaas SJ, Vogel LC. Pediatric spinal cord injury: transition to adulthood. J Voc Rehabil 1998; 10: 103-113.

18 Smith BM, Guihan M, LaVela SL, Garber SL. Factors predicting pressure ulcers in veterans with spinal cord injuries. Am J Phys Med Rehabil 2008; 87: 750-757.

19 Saunders LL, Krause JS. Psychological factors affecting alcohol use after spinal cord injury. Spinal Cord 2011; 49: 637-642.

20 Aubin HJ, Rollema H, Svensson TH, Winterer G. Smoking, quitting, and psychiatric disease: a review. Neurosci Biobehav Rev 2011; 36: 271-284.

21 Anderson CJ, Vogel LC, Chlan KM, Betz RB, McDonald CM. Depression in adults who sustained spinal cord injuries as children or adolescents. J Spinal Cord Med 2007; 30: S76-S82.

22 Fann JR, Bombardier CH, Richards JS, Tate DS, Wilson S, Temkin N. For the PRISMS investigators. Depression after spinal cord injury: comorbidities, mental health service use, and adequacy of treatment. Arch Phys Med Rehabil 2011; 92: 353-360.

23 Anderson CJ, Vogel LC. Employment outcomes of adults who sustained spinal cord injuries as children or adolescents. Arch Phys Med Rehabil 2002; 83: 791-801.

24 Krause JS, Saunders LL. Risk of hospitalizations after spinal cord injury: relationship with biographical, injury, educational, and behavioral factors. Spinal Cord 2009; 47: 692-697.

25 Cardenas DD, Jensen MP. Treatments for chronic pain in persons with spinal cord injury: a survey study. J Spinal Cord Med 2006; 29: 109-117.

26 Babor TF, Higgins-Biddle JC, Saunders JB, Monteiro MG. AUDIT The Alcohol Use Disorders Identification Test: Guidelines for use in primary care. 2nd edn. World Health Organization (WHO/MSD/MSB/01.6a): Geneva, 2001.

27 Swift W, Copeland J, Hall W. Choosing a diagnostic cut-off for cannabis dependence. Addiction 1998; 93: 1681-1692. 